\title{
Board 81: Work-in-Progress: Building an Inclusive Faculty Community through the Teaching and Learning Academy
}

\section{Dr. Jianyu "Jane" Dong, California State University, Los Angeles}

Jianyu Dong is a professor in electrical and computer engineering at CSULA and currently serves as the Associate Dean for the College of Engineering, Computer Science and Technology. Her area of expertise is video compression/communication, multimedia networks, QoS, etc. She has been engaged in multiple projects and initiatives in engineering education to increase the success of students from underserved low-income communities.

\section{Dr. Emily L. Allen, California State University, Los Angeles}

Emily L. Allen, Ph.D., is Dean of the College of Engineering, Computer Science, and Technology at California State University, Los Angeles. She earned her BS in metallurgy and materials science from Columbia University, and her MS and $\mathrm{PhD}$ in materials science and engineering from Stanford University. She previously served as faculty, chair and Associate Dean at San Jose State University's College of Engineering. Dr. Allen believes in a collaborative, student-centered approach to research, education and academic administration and leadership. She currently serves on the ASEE Engineering Deans Council Executive Board, the ABET Academic Affairs Council, and chairs the ABET Task Force on Diversity and Inclusion. 


\title{
Work-in-Progress: Building an Inclusive Faculty Community Through the ECST Teaching and Learning Academy
}

\begin{abstract}
This paper describes how the College of Engineering, Computer Science, and Technology (ECST) at Cal State LA developed a Teaching and Learning (T\&L) Academy as a platform to cultivate inclusive and collaborative culture. Originated as a one-day August workshop in 2015 to share best teaching practices within the college, and primarily aimed at newly hired tenure-track faculty members, the T\&L Academy now has expanded to include a series of short, informal faculty learning community meetings called Teacher-Scholar Forums throughout the academic year. The content of the summer workshop is designed collaboratively with the Center for Effective Teaching and Learning (CETL), which organizes the University New Faculty Orientation. In the past three years, we have seen the growth of participation of both junior and senior faculty, both tenured/tenure-track and adjunct faculty from different departments in the College. This Work-inProgress paper presents the evolving process of the T\&L Academy, as well as its impact on faculty integration and engagement. Preliminary data including faculty participation and survey results on perceived value of the T\&L Academy will be shared.
\end{abstract}

\section{Introduction}

Faculty engagement and integration has been well recognized as a key factor in the development of a positive college culture and a productive teaching and learning environment [1]. However, the independent nature of faculty work as well as the segmented institutional structure has led to the prevalence of academic silos. In addition, with the changing landscape and budgets of institutions of higher education, adjunct faculty who are hired through temporary contracts are playing an increasingly important role in undergraduate education. In the College of Engineering, Computer Science, and Technology (ECST) at Cal State LA, more than $50 \%$ of courses are taught by adjunct faculty, many of whom are current or former working professionals. Clearly the work experience and expertise of the adjunct faculty is a great asset to the institution, however, the lack of effective ways of integrating faculty into the college has presented a significant barrier to the establishment of an inclusive and supportive faculty community. In addition, in a unionized environment, bargaining unit rules may make it difficult to require adjunct faculty to attend professional development meetings.

In 2015, Inside Higher Ed conducted a Survey of College and University Faculty Workplace Engagement in conjunction with researchers from Gallup [2]. The survey results found that only about $34 \%$ of faculty are engaged in their workplace, meaning that they felt their opinions were valued, their work was meaningful and rewarding, and they had good interactions with colleagues. Among the faculty surveyed, tenure-track faculty showed a higher level of engagement (45\%) than their tenured colleagues as well as the adjunct faculty, where about $32 \%$ of either group are engaged. While a number of factors affected the faculty's perception towards engagement in the workplace such as job security, workload and compensation, a major reason for the difference in the engagement between tenure-track faculty and the others is the institution's effort in mentoring and providing professional development. Clearly, the Inside Higher Ed Survey results indicated significant needs for higher education institutions to take steps to increase faculty engagement. However, published research work in this area has been quite limited. In [3], Kathryn Q. Thirolf provided a comprehensive review of conceptual models of faculty/employee engagement and 
integration and proposed a more inclusive model that was applicable to community colleges. The new model pointed out that comprehensive faculty engagement should include four components: Orientation, Communication, Socialization, and Learning. Each component should have both academic and social elements to foster faculty growth and strengthen faculty affiliation with their colleagues. Examples of successful faculty engagement efforts at ATD (Achieve the Dream) Colleges [4] also highlighted the effectiveness of the social element.

This WIP paper presents a pilot effort conducted at the College of Engineering, Computer Science, and Technology at Cal State LA to increase faculty engagement and to build an inclusive faculty community. In the College's 2015-2020 strategic plan, a key strategic area is to "nurture a community of deeply engaged faculty and staff committed to enable student success through quality curriculum, responsive teaching and active learning". Launched in Summer 2015, the ECST Teaching \& Learning Academy was originally focused on professional development of new faculty members, but quickly evolved to be a platform for open communication, socialization, and shared learning for faculty across all disciplines in the college. In the past three years, we have seen the growth of participation of faculty, both tenured/tenure-track and adjunct faculty from different departments in the College. This rest of the paper describes the evolving process of the ECST Teaching and Learning Academy, its current structure, as well as its impact on faculty integration and engagement through preliminary data including faculty participation and survey results on the perceived value of the T\&L Academy. By sharing our work at an ASEE conference, we also expect to receive feedback to help us further enhance faculty engagement and integration.

\section{ECST Teaching and Learning Academy Structure}

The College of ECST launched the Teaching and Learning Academy (T\&L) in Summer 2015. The first T\&L event was a one-day summer workshop that highlighted the use of active learning in college teaching practice. The workshop was designed to be in conjunction with the University's New Faculty Orientation to engage our new faculty in evidence-based teaching strategies in engineering, computer science, and technology areas. Experienced faculty engaged in innovative education projects were invited to serve as speakers in the first summer workshop. Although the workshop was targeted towards the new faculty, it was open to all T/TT faculty as well as adjunct faculty in the college. About 30 faculty members attended the first workshop, and their feedback was overwhelmingly positive. Many participants asked for "more events like this for faculty to interact". In addition, while the participants recognized the value of learning useful teaching practice, almost all of them recommended to have more time for interaction with peers or students (e.g. a student panel conversation). Clearly, the feedback showed the importance of the social element in faculty development and pointed out a lack of such opportunities.

During the past three years, we revised the structure and components of the ECST T\&L Academy multiple times based on faculty suggestions. Currently, the T\&L Academy consists of a summer workshop and a series of short, informal faculty learning community meetings called TeacherScholar Forums throughout the academic year. The Summer workshop uses "theme-based" design to introduce teaching and learning-related scholarly work to our faculty, while the Forums feature faculty-led discussions on their own ideas, practices, thoughts and questions. Table 1 lists the T\&L academy summer workshop topics and some representative discussion topics in the year-round Teacher-Scholar Forums. The duration of the summer workshop is usually 1-day (reduced to 6 hours in 2018), and the monthly forum typically lasts one hour and a half. The summer workshop 
is required for new tenure-track faculty to attend, whereas it is voluntary for everyone else, as are the monthly Forums.

Table 1. Representative ECST T\&L Summer Workshop and Teacher-Scholar Forum Topics.

\begin{tabular}{|c|c|}
\hline T\&L Academy Summer Workshop & Teacher-Scholar Forum \\
\hline $\begin{array}{l}\text { 2015: Active learning strategies to } \\
\text { enhance student success } \\
\text { 2016: Creating an inclusive and engaging } \\
\text { learning experience } \\
\text { 2017: Strategies for effective mentoring } \\
\text { 2018: Rewarding teaching and learning } \\
\text { experiences }\end{array}$ & $\begin{array}{l}\text { - Who are our students: sharing ideas/practice to address our } \\
\text { students' learning needs } \\
\text { - } \quad \text { Effective Learning Assessment } \\
\text { - } \quad \text { Rongineering Education Grant ABC } \\
\text { - } \text { years in classroom } \\
\text { - } \quad \text { Five effective strategies of teaching } \\
\text { - } \quad \text { Analysis of Effectiveness of LaunchPad program } \\
\text { - } \quad \text { Flipped ME2040: course structure and student performance }\end{array}$ \\
\hline
\end{tabular}

In line with the faculty engagement model proposed by Kathrin as well as the faculty feedback, all T\&L Academy events have both academic and social emphasis. A typical agenda for Summer Workshop includes one featured presentation or training session led by invited speakers that help our faculty to gain new knowledge, skills or insight, plus multiple social activities that foster conversation, reflection, and shared-learning among participants. The topics of the summer workshop and the forums are solicited through a faculty survey to make sure that the contents of T\&L events are aligned with the faculty interest. In addition to face-to-face meetings, a Moodle site for the T\&L Academy has been established to share workshop and forum presentations as well as useful educational resources. In addition, the Moodle site serves as an asynchronous forum for our faculty to continue their conversation beyond the organized meetings.

\section{Faculty Participation and Perception}

Table 2 shows the number of participants in the past four T\&L Summer workshops. In Fall 2018 the participation rate for T/TT faculty $(\sim 45 \%)$ was much higher than for the adjunct faculty $(\sim 14 \%)$ since most adjunct faculty teach part-time or have other jobs and their availability is limited. In addition new T/TT faculty are required to participate while it is completely voluntary for adjunct faculty. Nevertheless it was encouraging to see participants came from all departments in the college. In 2018, we also had two adjunct faculty beyond our college (one in Math and the other in Physics) joining us in the event. The Math and Physics faculty are involved in our summer bridge program and our First-Year Experience programs. As for the monthly Teacher-Scholar forum, the participation in the initial meetings were low (4-5 people), but has grown to an average of 10 participants per meeting in the last two years.

Table 2. Participation in T\&L Academy Summer Workshop 2015-2018

\begin{tabular}{|l|c|c|c|c|c|c|}
\hline & $\begin{array}{c}\text { Total } \\
\text { Participants }\end{array}$ & $\begin{array}{c}\text { New tenure- } \\
\text { track faculty }\end{array}$ & $\begin{array}{c}\text { Other T/TT } \\
\text { faculty }\end{array}$ & $\begin{array}{c}\text { College Total } \\
\text { T/TT faculty }\end{array}$ & $\begin{array}{c}\text { Adjunct } \\
\text { Faculty }\end{array}$ & $\begin{array}{c}\text { College } \\
\text { Total } \\
\text { Adjuncts }\end{array}$ \\
\hline 2015 & 30 & 5 & 19 & 40 & 6 & 102 \\
\hline 2016 & 37 & 8 & 19 & 48 & 10 & 104 \\
\hline 2017 & 30 & 3 & 20 & 50 & 7 & 105 \\
\hline 2018 & 34 & 4 & 21 & 55 & 9 & 65 \\
\hline
\end{tabular}


To gauge the impact of the T\&L Academy on faculty development and community building, a faculty perception survey was conducted after the Summer Workshop. Figure 1 shows the 2018 faculty response $(\mathrm{N}=22)$ to three survey questions:1) I learned something useful from the event (value to self); 2) I will recommend my colleagues to attend future T\&L Academy event (value to other colleagues); 3) The event helped to enhance faculty community in the college.

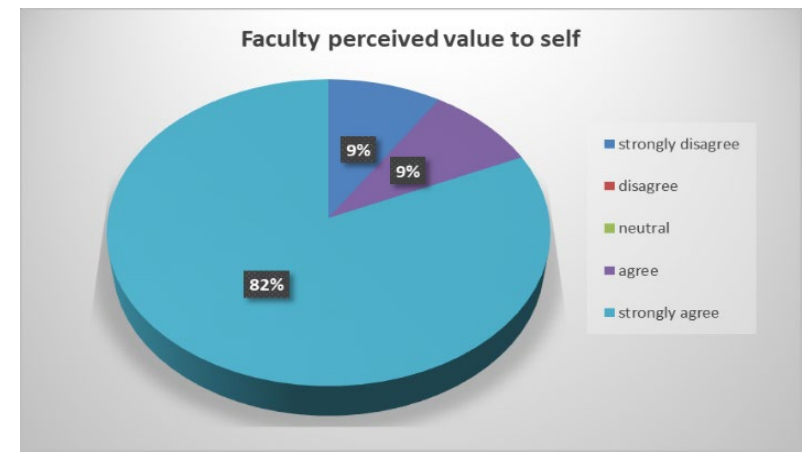

(a)

(b)

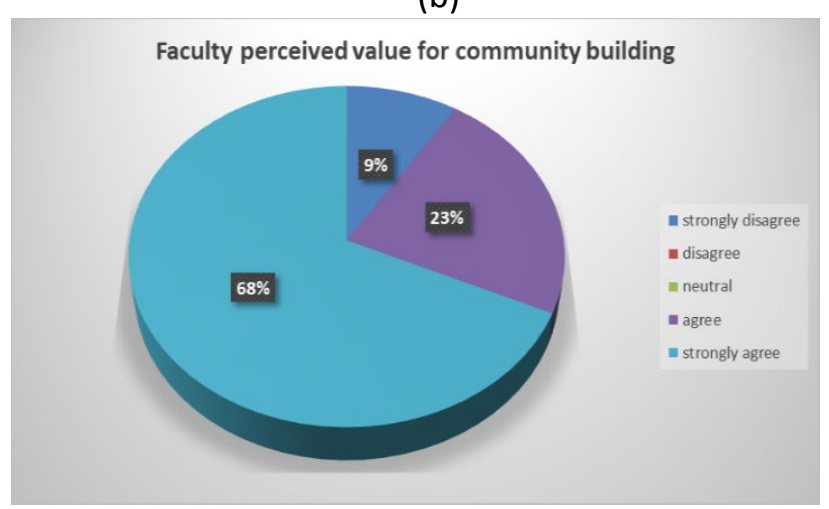

(c)

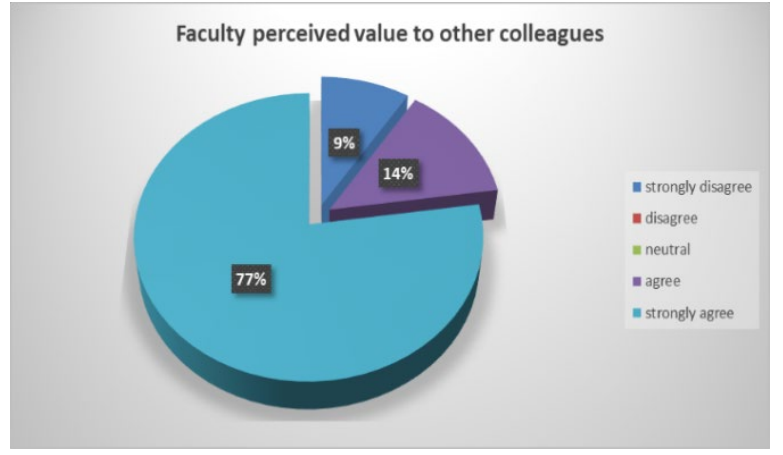

The survey results clearly show that most participants thought the summer workshop was valuable to their self-development and that of their colleagues. In addition, 91\% of participants agreed that the T\&L event positively contributed to faculty community building in the college. So far we have not conducted a survey regarding the Teacher-scholar forums. More comprehensive assessment will be developed in the future to measure the overall impact, such as determining whether faculty have utilized new techniques learned in the program.

Figure 1. Result of faculty perception survey.

\section{Future Work and Conclusions}

This paper presents the development of ECST T\&L Academy as a platform for both faculty development and community building. Its functionality has been confirmed through the preliminary data collected from a faculty survey. Additional qualitative feedback from chairs and faculty indicated that T\&L Academy helped new faculty to adopt student-centered teaching strategies and become reflective instructors. However, increasing the participation of more adjunct faculty still remains a challenge. We plan to formulate a more structured study to better understand the effectiveness of the T\&L Academy and to guide the future steps in enhancing faculty engagement and integration.

\section{Reference}

[1] Bersin, J. (2015). Becoming irresistible: A new model for employee engagement. Deloitte Review, 2015 (16), $146-163$.

[2] Colleen Flaherty, "Going Through the Motions? The 2015 Survey of Faculty Workplace Engagement," Inside Higher Ed. Oct 23, 2015 
[3] Kathryn Q. Thirolf, "Reconceptualizing a More Inclusive Faculty Engagement Model: Including and Engaging Part-time Faculty at Community Colleges," Community College Journal of Research and Practice, 2017 Vol. 41, No. 4-5

[4] Public Agenda (2011), "Engaging Adjunct and Full-time Faculty in Student Success Innovation", https://www.publicagenda.org/media/engaging-adjunct-and-fulltime-faculty-in-student-success-innovation 